\title{
Multiple effects of exotic largemouth bass (Micropterus salmoides) and environmental factors on species richness and composition of pond-dwelling fishes
}

\author{
Hiroshi TsunODA ${ }^{1,2, a}$ and Yoshito MITSUO ${ }^{3}$ \\ ${ }^{1}$ Faculty of Agriculture, Tokyo University of Agriculture and Technology, 3-5-8 Saiwaicho, Fuchu, 183-8509 Tokyo, Japan \\ 2 Research Center for Wildlife Management, Gifu University, 1-1 Yanagido, 501-1193 Gifu, Japan \\ ${ }^{3}$ Faculty of Science and Technology, Ryukoku University, 1-5 Yokotani, Seta Oe, 520-2194 Otsu, Japan
}

Received 3 April 2012; Accepted 6 June 2012

\begin{abstract}
The presence of piscivorous fish has a significant effect on the structure of fish assemblages. Exotic, piscivorous largemouth bass (Micropterus salmoides) have been introduced to a number of Japanese farm ponds that were originally characterized by a high level of biodiversity. We evaluated the effects of exotic bass on the structure of the fish assemblage following their introduction into the farm ponds. We collected fish and measured environmental conditions in 14 ponds of northeastern Japan. The species richness of pond-dwelling fish assemblages was negatively correlated with the relative abundance of exotic bass. In addition, the relative abundance of lentic cyprinid species (e.g., Rhodeus ocellatus ocellatus, Pseudorasbora parva and Carassius sp.) was negatively correlated with the relative abundance of exotic bass. The abundance of these species was also influenced by environmental factors, including transparency and/or coverage of aquatic vegetation, likely related to their influence on the predatory efficiency of exotic bass. Our results suggest that the structure of fish assemblages in farm ponds with exotic piscivorous fish was influenced by both biotic (i.e., predation) and abiotic factors and that some environmental factors mediate the effects of exotic bass on fish species richness and composition.
\end{abstract}

Keywords: Freshwater fish / Exotic piscivore / Pond environments / Fish assemblage / Prey-predator interaction / Micropterus salmoides

\section{Introduction}

The problem of introduced organisms is one of the major factors causing a loss of biodiversity in aquatic ecosystems (Moyle and Light 1996; Rahel 2002). In freshwater systems, the introduction of invasive predatory fish has a serious impact on aquatic communities and alters ecosystem processes (Kaufman 1992; Jackson et al. 2001; Maezono et al. 2005). The impact of predators affects several trophic levels via direct and indirect effects (Strong 1992; Polis and Strong 1996). The largemouth bass (Micropterus salmoides) is a piscivorous fish (Centrarchidae) from North America that has been introduced to more than 50 countries (Welcomme 1992) and has the potential to dramatically change the food-web structure of freshwater systems (Keast and Webb 1966; Jackson et al. 2001; Jackson 2002). The species was introduced to Japan in 1925 for the purpose of sport fishing and aquaculture (Kaneko and Wakabayashi 1998), and had spread across many Japanese lakes and ponds by 2000 (Yodo and Iguchi 2004). Although

a Corresponding author: tsunoda@gifu-u.ac.jp largemouth bass broadly affect several trophic levels and alter food-web structures in freshwater systems (Maezono et al. 2005), their predatory impacts on prey assemblages are of significant concern in Japan. A number of studies have reported a degradation of species richness of local fish fauna and extinction of local fish populations in Japanese lakes and ponds following invasions of largemouth bass (Azuma and Motomura 1998; Maezono and Miyashita 2003; Abekura et al. 2004; Sugiyama and Jinguji 2005; Tsunoda et al. 2010).

The structuring of fish assemblages is shaped by both biotic and abiotic factors, and predation by piscivores is one of the major influencing factors (Tonn et al. 1990; Jackson et al. 2001). Some previous studies have reported that smallbodied species, such as small cyprinids, mosquitofish (Gambusia affinis), or stickleback (Culaea inconstans) do not cooccur with piscivorous fish (Tonn and Magnuson 1982; Rahel 1984; Tonn et al. 1990; Godinho and Ferreira 1998; MacRae and Jackson 2001) and are eliminated from systems following their introduction (Chapleau et al. 1997; Nowlin et al. 2006). On the other hand, environmental factors such as dissolved oxygen and vegetation coverage are also associated 
with the structuring of fish assemblages including piscivorous species (Tonn and Magnuson 1982; Rahel 1984). These factors affect predatory performance and the efficiency of piscivorous species, and alter prey-predator interaction. For example, increasing habitat structural complexity with aquatic macrophytes, rocks, or coarse woody materials decreases predatory effectiveness by providing refuge for prey (Savino and Stein 1982, 1989; Gotceitas and Colgan 1989; Persson and Eklöv 1995; Warfe and Bramuta 2004; Sass et al. 2006). Thus, the structuring of fish assemblages including piscivorous species could be associated with both prey-predator interaction and its related environmental factors. Although these patterns may extend to native fish assemblages with exotic predators, they have not been well-documented in the case of exotic bass in Japanese freshwater systems.

In Japan, although farm ponds are generally artificial habitats for agricultural irrigation, they contain a variety of freshwater organisms (e.g. Kadono 1998; Mitsuo et al. 2010) and are required for the maintenance of aquatic biodiversity in agricultural landscapes. Largemouth bass have been introduced to and established in small farm ponds, and the predatory impact of this species is likely to be exacerbated in these habitats compared with large lakes. For example, in small ponds, fish species richness decreases dramatically with few or no native species remaining after the invasion of bass (Maezono and Miyashita 2003; Yonekura et al. 2004; Sugimura and Jinguji 2005; Tsunoda et al. 2010).

The objectives of the present study were to determine the gradient in effects of exotic largemouth bass on the structuring of pond-dwelling fish assemblages and its influencing factors. We hypothesized that fish species richness and composition vary among ponds with exotic bass, because the predatory efficiency of this species is mediated by the unique environmental characteristics of the ponds. We surveyed fish assemblages and environmental factors among several ponds within an agricultural irrigation system and analyzed the relationships between them.

\section{Materials and methods}

\subsection{Study area}

The farm ponds $(N=14)$ were located on an alluvial fan in upper Kitakami River basin of Iwate prefecture, northeastern Japan $\left(141^{\circ} 01^{\prime}-06^{\prime}\right.$ E, $39^{\circ} 04^{\prime}-07^{\prime}$ N; Fig. 1). The Kitakami River is the fourth largest river in Japan (total length: $249 \mathrm{~km}$, total basin area: $10150 \mathrm{~km}^{2}$ ) and flows into the Pacific Ocean through Iwate and Miyagi prefecture. The river basin is covered with forests $(78 \%)$, paddy (14\%) and dry fields (5\%), and settlements and urban areas (3\%). Farm ponds are mainly found in agricultural areas. The mean surface area and maximum depth of the studied ponds were $13500 \mathrm{~m}^{2}$ (range: 1400 50500 ) and $1.9 \mathrm{~m}$ (range: 0.8-5.9), respectively. All ponds had an inflow channel that was connected to a stream. Each of the ponds was originally constructed for the purpose of irrigation for rice farming and a barrier (i.e. irrigation plant) was installed downstream of all ponds, interrupting the immigration of fish from the downstream direction. Largemouth bass were the only piscivorous fish at these sites (Mitsuo et al. 2010, 2011).
Although largemouth bass were introduced to Iwate Prefecture after the 1990s (Yodo and Iguchi 2004), the exact time of their introduction to the ponds is unknown. There were no fisheries or aquaculture, with the exception of private recreational fishing at the study sites.

\subsection{Field surveys}

We surveyed the fish fauna in each of 14 ponds in June, August and October of 2009, but not during winter when the pond surfaces were frozen. Two cast nets $(9.5 \mathrm{~mm}$ and $27.5 \mathrm{~mm}$ meshes), two dip nets (1 mm mesh) and three minnow traps (60 mm diameter entrance) were used for sampling fish populations. We used fishing bait (Marukyu Co., Ltd., Saitama, Japan) to compensate for the short saturation time of the minnow trap. The sampling times were dependent on the pond size (range: 30-120 $\mathrm{min}$ ). Fish were collected throughout the pond (i.e., at different depths and open/vegetated locations) to account for the range of microhabitats within the ponds. We used a boat to capture fish at offshore sites. The collected fish were kept alive during sampling, and species were identified and the number of individuals in each species was counted in situ. Although two species of the genus Carassius (C. cuvieri and $C$. auratus langsdorfii) appeared in the samples, they were treated as Carassius sp. because of the difficulty in identifying the juveniles in situ. All individuals excluding largemouth bass were released back into the same ponds.

We also surveyed and measured the following physical and chemical environmental factors of the ponds: surface area $\left(\mathrm{m}^{2}\right)$, mean water depth $(\mathrm{m})$, dissolved oxygen $\left(D O, \mathrm{mg} \mathrm{L}^{-1}\right)$, electrical conductivity $\left(E C, \mu \mathrm{S} \mathrm{cm}^{-1}\right), \mathrm{pH}$, transparency $(\mathrm{cm})$, coverage of emergent and floating aquatic plants $(\%)$, coverage of the pond shore by a concrete bank $(\%)$, distance to the main channel $(\mathrm{m})$, and size of the inflow channel $(\mathrm{cm})$. Using a field device (PS-7FL, Honda Electronics Inc., Tokyo, Japan) and a boat, we calculated the mean depth from measurements taken at ten locations equally spaced within the pond. $D O, E C, \mathrm{pH}$ and transparency were measured by field devices (DO: $D O$ 5 509, Fuso Inc., Tokyo, Japan; EC: B-173 and pH: B-212, Horiba Inc., Tokyo, Japan) and a turbidity tube (AT-3: Hoga Inc., Kyoto, Japan), respectively. Coverage of the pond surface by emergent and floating aquatic plants and coverage of the pond shore by a concrete bank were measured by sight and recorded on a map (1:3000). In the laboratory, we measured area of vegetation coverage and distance of concrete-covered shore using planimeter (KP-92N, Edenki Inc., Kyoto, Japan) and scale respectively, and then calculated percentage. Size of the inflow channel was directly measured in the field. The surface area and distance to the main channel (the shortest distance from each pond to a channel with a width $>1.5 \mathrm{~m}$ ) were measured using a map (1:25000).

\subsection{Statistical analysis}

To determine the effect of exotic largemouth bass on the species composition of pond-dwelling fish assemblages, we used non-metric multidimensional scaling (NMDS, BrayCurtis distance) using the relative abundance of fish species. In 

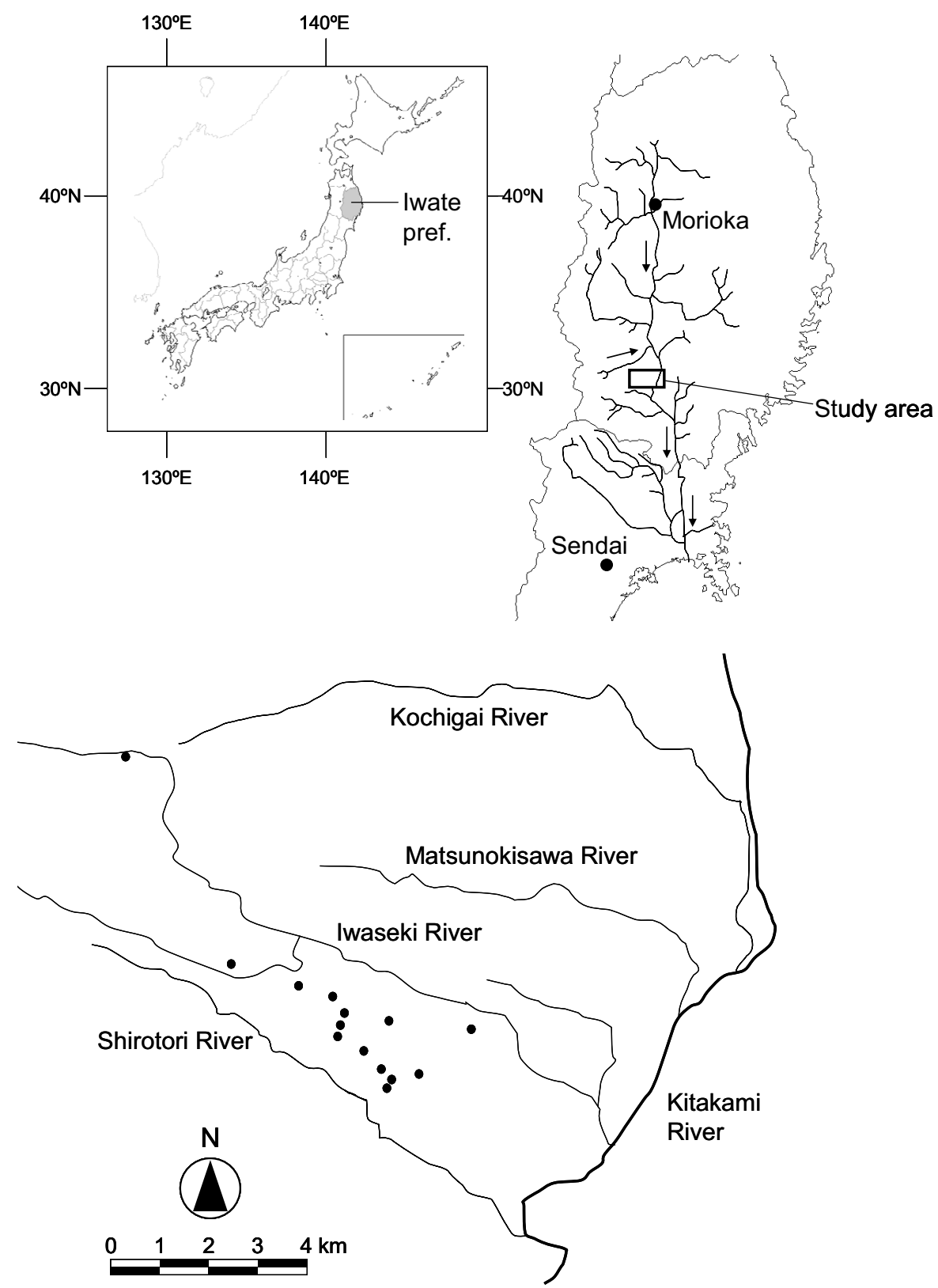

Fig. 1. The study area (above) and location of sampled ponds (below, Solid circles and lines represent the ponds and streams with a width $>5.0 \mathrm{~m}$, respectively).

addition, to determine factors influencing fish species richness and relative abundance, we used Spearman's rank correlation. Before the analysis, we used a principal components analysis (i.e. $P C A$ ) to summarize variance in the environmental factors. The number of fish species occurring, relative abundances of fish species and $P C A$ scores for environmental variables were used for the analysis. For the analyses of relative abundance, since the three species (Hypomesus nipponensis, Cobitis biwae and Pseudobagrus tokiensis) occurred in one or two studied ponds, we used variables of common species (occurring in $>40 \%$ of the studied ponds, see Table 2).

For NMDS, we used R ver. 2.10.1 (R Development Core Team 2009) and the "metaMDS" function in the vegan package (Oksanen et al. 2008). The analyses excluding NMDS were conducted using Excel Statistics ver. 2008 (ESRI Inc., Tokyo, Japan).

\section{Results}

\subsection{Effects of predominance of exotic bass on species composition of fish assemblages}

A total of 11 species including largemouth bass were observed in the study ponds (Table 2). Mean \pm SD of species richness (excluding bass) and relative abundance 
of largemouth bass among the ponds were $4.9 \pm 2.3$ (range: $1-9$ species) and $37.4 \pm 28.2 \%$ (range: $0.6-95 \%$ ) of collected fish (Table 3 ), respectively.

The NMDS on relative abundance of fish species yielded a two axis optimal solution with a final stress value of 12.1, which is within the range (10.0-20.0) commonly observed in community data. In the ordination plot, five of ten species (Rhodeus ocellatus ocellatus, Pseudorasbora parva, Carassius sp., $H$. nipponense and $P$. tokiensis) were separated from largemouth bass by NMDS axis 1 (Fig. 2a). The ordination plot also showed that ponds less-predominated by largemouth bass (G-N; see Table 3) were separated by NMDS axis 1 and mainly plotted on the second and third quadrants (Fig. 2b).

\subsection{Factor influencing fish species richness and relative abundance}

The first three axes of the PCA explained $70.94 \%$ of the variance in environmental factors. $P C 1$ explained $34.03 \%$, and was positively related to mean depth ( $P C$ score: 0.89$), D O(P C$ score: 0.78$)$ and size of the inflow channel $(P C$ score: 0.71 ; Table 1). $P C 2$ explained $24.01 \%$, and was negatively related to transparency ( $P C$ score: -0.74$). P C 3$ explained $16.50 \%$ and was positively related to coverage of floating ( $P C$ score: 0.94$)$ and emergent plants ( $P C$ score: 0.74$)$ (Table 1).

Fish species richness had a highly significant negative correlation with the relative abundance of exotic bass ( $r s=$ $-0.893, p<0.0001$; Fig. 3). Moreover, species richness positively correlated with environmental $P C 2$ scores $(r s=0.637$, $p<0.05)$ and negatively correlated with environmental $P C 3$ scores $(r s=-0.579, p<0.05$; Fig. 3 ). There was a weak positive correlation between species richness and environmental $P C 1$ scores ( $r s=0.200$, n.s.; Fig. 3).

The relative abundance of exotic bass negatively correlated with environmental PC2 scores $(r s=-0.604, p<0.05$ ), whereas there were no significantly correlation with environmental PC1 ( $r s=-0.182$, n.s.) and PC3 scores ( $r s=0.354$, n.s.). The relative abundances of six out of seven common species negatively correlated with the relative abundance of exotic bass (Table 4), and three of them, R. ocellatus ocellatus, P. parva and Carassius sp., were statistically significant negative correlations $(r s=-0.840, p<0.001 ; r s=-0.791$, $p<0.001$; and $r s=-0.571, p<0.05$, respectively; Table 4). Environmental $P C 2$ scores positively correlated with relative abundances of both $P$. parva $(r s=0.613, p<0.05)$ and Carassius sp. ( $r s=0.633, p<0.05)$. Moreover, environmental $P C 1$ and $P C 3$ scores positively correlated with the relative abundance of Zacco platypus $(r s=0.613, p<0.05)$ and negatively correlated with the relative abundance of $P$. parva $(r s=-0.620, p<0.05)$.

\section{Discussion}

\subsection{Effects of exotic largemouth bass on species richness and composition}

The present study showed that a predominance of exotic largemouth bass was the main factor decreasing species richness and altering the species composition of pond-dwelling
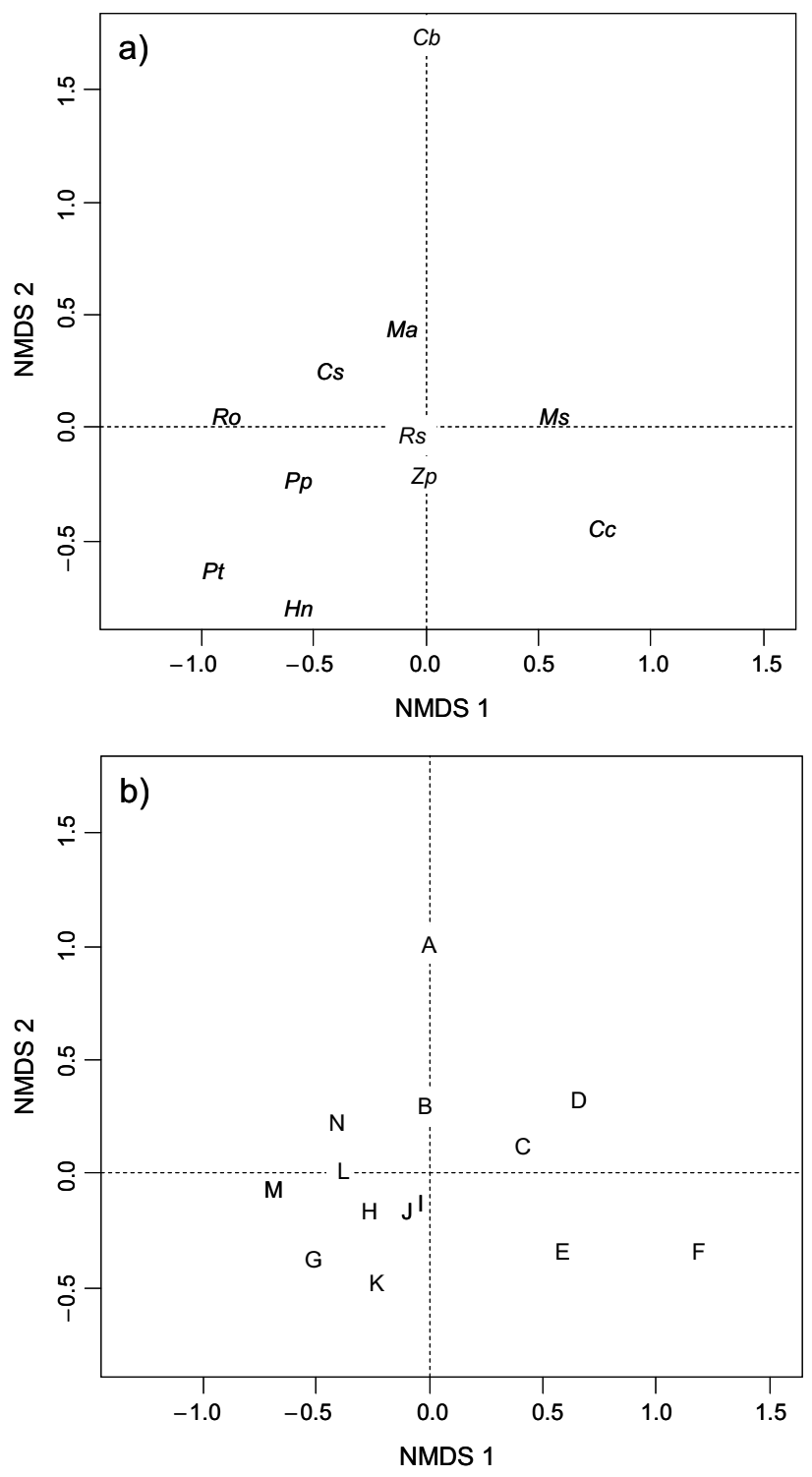

Fig. 2. Ordination plots of fish species (a) and 14 farm ponds (b) based on relative abundances of fish species along non-metric multidimensional scaling (NMDS: Stress value $=12.1$ ). (a) The italics represent fish names as following: $C b$ : Cobitis biwae, $C c$ : Cyprinus carpio, Cs: Carassius sp., Hn: Hypomesus nipponensis, Ma: Misgurunus anguillicaudatus, Ms: Micropterus salmoides, Pp: Pseudorasbora parva, Pt: Pseudobagrus tokiensis, Ro: Rhodeus ocellatus ocellatus, Rs: Rhinogobius sp., Zp: Zacco platypus. (b) The letters represent farm pond codes $(\mathrm{A}-\mathrm{N})$.

fish assemblages. Some previous studies reported that the presence or predominance of piscivorous fish is a critical factor in the structuring of fish assemblages (Tonn et al. 1990; Whittier and Kincaid 1999; Jackson et al. 2001; Bertolo and Magnan 2006). In the case of largemouth bass, previous studies in small pond systems $\left(<10000 \mathrm{~m}^{2}\right)$ of Japan showed that no or few species survived after bass invasion (Maezono and Miyashita 2003; Yonekura et al. 2004; Sugimura and Jinguji 2005; Tsunoda et al. 2010). In addition, Jackson et al. (2001) identified that the coexistence of small cyprinids and 
Table 1. Mean, standard deviation (SD), range, and factor loadings for environmental variables in the principal component $(P C)$ analysis of the 14 farm ponds in northeastern Japan.

\begin{tabular}{lcccccc}
\hline & & & & \multicolumn{3}{c}{$P C$ factor loading } \\
\cline { 4 - 7 } & Mean & SD & Range & $P C 1$ & \multicolumn{2}{c}{$P C 2$} \\
\hline Surface area $\left(\mathrm{m}^{2}\right)$ & 13843 & 11979 & $1700-50500$ & 0.68 & -0.19 & 0.42 \\
Mean depth $(\mathrm{m})$ & 1.4 & 0.7 & $0.5-2.8$ & 0.89 & -0.19 & 0.02 \\
$D O(\mathrm{mg} / \mathrm{L})$ & 5.9 & 0.5 & $5.1-6.7$ & 0.78 & 0.14 & -0.20 \\
$\mathrm{pH}$ & 7.8 & 0.3 & $7.4-8.5$ & 0.68 & 0.55 & -0.04 \\
$E C(\mu \mathrm{s} / \mathrm{cm})$ & 86.6 & 10.9 & $65.3-107.3$ & 0.32 & 0.67 & -0.07 \\
Transparency $(\mathrm{cm})$ & 38.1 & 28.4 & $9.0-100.0$ & 0.49 & -0.74 & 0.16 \\
Emersed vegetation coverage $(\%)$ & 4.4 & 4.5 & $0-15$ & -0.27 & 0.38 & 0.74 \\
Floating vegetation coverage $(\%)$ & 10.2 & 16.4 & $0-41$ & 0.15 & -0.16 & 0.94 \\
Shoreline covered with concrete $(\%)$ & 41.9 & 32.1 & $0-98$ & 0.61 & -0.55 & -0.18 \\
Size of inflow channel $(\mathrm{cm})$ & 63.3 & 43.3 & $25-184$ & 0.71 & 0.38 & -0.15 \\
Distance to closest channel $(\mathrm{m})$ & 414 & 225 & $0-722$ & -0.33 & -0.49 & -0.28 \\
\hline
\end{tabular}

Table 2. Frequency of occurrence (\%) of fish species collected in 14 farm ponds in northeastern Japan.

\begin{tabular}{lccc}
\hline Species name & Life type & Tolerance to hypoxia & Frequency occurrence $(\%)$ \\
\hline Micropterus salmoides & Pelagic & Intolerant & $14(100)$ \\
Misgurunus anguillicaudatus & Demersal & Tolerant & $12(85.7)$ \\
Rhinogobius sp. & Demersal & Intolerant & $12(85.7)$ \\
Carassius sp. & Pelagic & Tolerant & $10(71.4)$ \\
Zacco platypus & Pelagic & Intolerant & $8(57.1)$ \\
Pseudorasbora parva & Pelagic & Tolerant & $8(57.1)$ \\
Cyprinus carpio & Pelagic & Tolerant & $6(42.9)$ \\
Rhodeus ocellatus ocellatus & Pelagic & Intolerant & $6(42.9)$ \\
Hypomesus nipponensis & Pelagic & Intolerant & $2(14.3)$ \\
Cobitis biwae & Demersal & Tolerant & $1(7.1)$ \\
Pseudobagrus tokiensis & Demersal & Intolerant & $1(7.1)$ \\
\hline
\end{tabular}

Table 3. The relative abundance (\%) of occurred fish species in each studied pond.

\begin{tabular}{|c|c|c|c|c|c|c|c|c|c|c|c|c|c|c|c|}
\hline \multirow[t]{2}{*}{ Family } & \multirow[t]{2}{*}{ Species } & \multicolumn{14}{|c|}{ Pond code } \\
\hline & & $\overline{\mathrm{A}}$ & B & $\mathrm{C}$ & $\mathrm{D}$ & $\mathrm{E}$ & $\mathrm{F}$ & $\mathrm{G}$ & $\mathrm{H}$ & I & $\mathrm{J}$ & $\mathrm{K}$ & $\mathrm{L}$ & $\mathrm{M}$ & $\mathrm{N}$ \\
\hline \multirow[t]{5}{*}{ Cyprinidae } & Zacco platypus & & 12.1 & 2.4 & & 13.1 & & 7.9 & 8.0 & & 3.7 & 0.5 & & 2.6 & \\
\hline & Pseudorasbora parva & & & & & & & 31.3 & 42.0 & 29.7 & 25.9 & 12.8 & 14.4 & 20.0 & 4.9 \\
\hline & Cyprinus carpio & & & & & 1.6 & 5.0 & & 0.3 & 1.4 & 1.9 & 1.8 & 0.7 & & \\
\hline & Carassius sp. & 12.3 & 18.9 & & & & & 3.1 & 8.9 & 1.4 & 5.6 & 2.3 & 21.6 & 4.1 & 1.5 \\
\hline & Rhodeus ocellatus ocellatus & & & & & & & 2.2 & 0.6 & & & 1.8 & 1.3 & 49.5 & 46.3 \\
\hline \multirow[t]{2}{*}{ Cobitoidae } & Misgurunus anguillicaudatus & 40.2 & 9.8 & 4.7 & 1.9 & & & 12.0 & 2.7 & 6.1 & 1.9 & 0.5 & 3.9 & 1.8 & 3.0 \\
\hline & Cobitis biwae & 1.6 & & & & & & & & & & & & & \\
\hline Gobiidae & Rhinogobius sp. & & 16.7 & 39.2 & 37.7 & 6.6 & & 34.0 & 27.4 & 25.9 & 22.2 & 58.9 & 51.0 & 21.4 & 14.8 \\
\hline Osmeridae & Hypomesus nipponensis & & & & & & & 0.2 & & & & 0.9 & & & \\
\hline Bagridae & Pseudobagrus tokiensis & & & & & & & 4.1 & & & & & & & \\
\hline Centrarchidae & Micropterus salmoides & 45.9 & 42.4 & 53.8 & 60.4 & 78.7 & 95.0 & 5.3 & 10.1 & 35.4 & 38.9 & 20.5 & 7.2 & 0.6 & 29.6 \\
\hline \multicolumn{2}{|c|}{ Total number of collected fishes } & 122 & 132 & 212 & 53 & 61 & 20 & 418 & 336 & 212 & 54 & 219 & 153 & 541 & 203 \\
\hline
\end{tabular}

centrarchidae piscivores (i.e. the bass) was observed only in large lakes exceeding $1.5-2.0 \mathrm{~km}^{2}$ of surface area.

In the present study, however, the number of fish species occurring in ponds less-predominated by exotic bass (pond $\mathrm{G}-\mathrm{N}$ ) was nearly as high as that in bass-absent ponds in the region (see Mitsuo et al. 2010, 2011 and Table 3). MacRae and Jackson (2001) also reported that species richness of fish assemblages with and without smallmouth bass
(M. dolomieu) did not significantly differ, while species composition and abundance distinctly differed between them. Tonn and Magnuson (1982), and Rahel (1984) reported that fish fauna in northern Wisconsin small lakes were classified into two types, piscivore-predominant (centrarchids and/or Esox) or other species-predominant (Umbra-cyprinid or UmbraPerca). In the present study, the assemblages in the ponds of $\mathrm{G}-\mathrm{N}$ (i.e. less-predominated by exotic bass) were mainly 

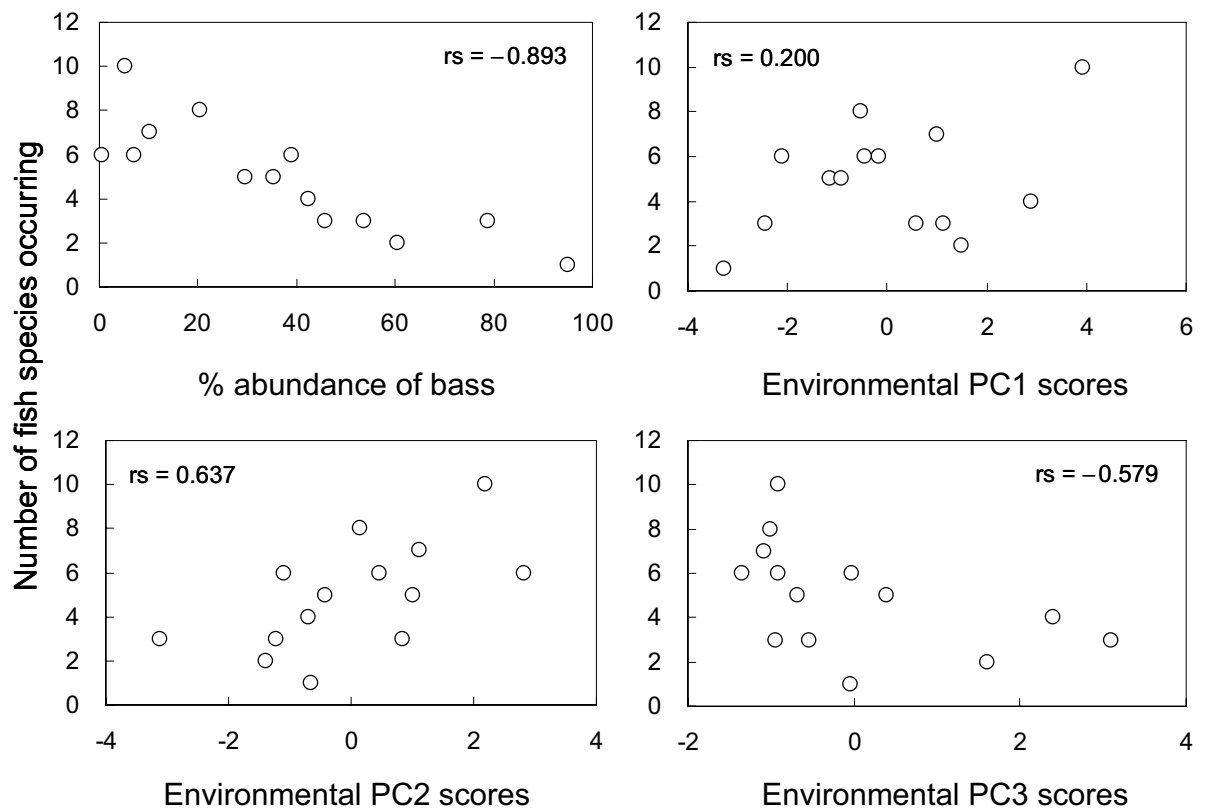

Fig. 3. Correlation between species richness of pond-dwelling fish assemblages and relative abundance of exotic largemouth bass and environmental principal component $(P C)$ scores $(P C$ 1: positive relationships with mean depth, $D O$ and size of inflow; $P C 2$ : negative relationship with transparency; $P C 3$ : positive relationships with coverage of floating and emergent vegetation).

Table 4. Results of Spearman's rank correlation between the relative abundance of pond-dwelling fish, the relative abundance of exotic largemouth bass, and environmental principal component $(P C)$ scores.

\begin{tabular}{lccccc}
\hline \multirow{2}{c}{ Species $^{\mathrm{a}}$} & & \%obundance & \multicolumn{2}{c}{$P C$ scores of pond environment } \\
\cline { 3 - 6 } & & of bass & $P C 1^{\mathrm{b}}$ & $P C 2^{\mathrm{c}}$ & $P C 3^{\mathrm{d}}$ \\
\hline Misgurunus anguillicaudatus & $(6.3 \%)$ & -0.229 & 0.178 & 0.339 & 0.365 \\
Rhinogobius sp. & $(25.4 \%)$ & -0.425 & 0.356 & 0.103 & -0.427 \\
Carassius sp. & $(5.7 \%)$ & $-0.571^{*}$ & 0.009 & $0.633^{*}$ & 0.084 \\
Zacco platypus & $(3.6 \%)$ & -0.112 & $0.613^{*}$ & -0.130 & -0.403 \\
Pseudorasbora parva & $(12.9 \%)$ & $-0.791^{* *}$ & 0.043 & $0.613^{*}$ & $-0.620^{*}$ \\
Cyprinus carpio & $(0.9 \%)$ & 0.228 & -0.500 & 0.087 & -0.415 \\
Rhodeus ocellatus ocellatus & $(7.3 \%)$ & $-0.840^{* *}$ & 0.151 & 0.472 & -0.221 \\
\hline
\end{tabular}

$* p<0.05, * * p<0.001$ (Spearman's rank correlation).

a mean percentage abundances of fish species in each pond is given in parenthesis.

${ }^{\mathrm{b}}$ positive relationships with mean depth, $D O$ and size of inflow.

${ }^{c}$ negative relationship with transparency.

${ }^{d}$ positive relationships with coverage of floating and emergent vegetation.

predominated by small-sized species such as Rhinogobius sp., $P$. parva or $R$. ocellatus ocellatus, which are vulnerable prey for bass across Japanese lakes and ponds (e.g. Yodo and Kimura 1998; Kuge et al. 2004; Tsunoda et al. 2009).

\subsection{Multiple effects of exotic largemouth bass and environmental factors on fish assemblages}

While exotic bass affected fish assemblages in the studied ponds, it was likely that the magnitude of effects varied among the ponds and species in the present study. Previous studies showed that the structuring of fish assemblages including piscivorous species is also influenced by physical and/or chemical environmental factors (Tonn and Magnuson 1982;
Rahel 1984), and that they can alter predatory efficiency and change the outcome of prey-predator interactions (Jackson et al. 2001). The results of the present study indicated that the species richness of pond-dwelling fish assemblages was negatively related to both transparency (negative factor on $P C 2$ ) and vegetation coverage (positive factor on PC3; see Table 1, Figs. 3 and 4). On the other hand, the relative abundance of exotic bass was positively related to transparency (Fig. 4) but showed weak-correlation with vegetation coverage. Transparency is related to underwater visibility because light intensity declines with increasing water turbidity (Brönmark and Hansson 2005). Since largemouth bass are visual predators (Howick and O'Brien 1983), their predatory efficiency decreases with increasing water turbidity (Reid et al. 1999; Shoup and Wahl 2009). On the other hand, aquatic 

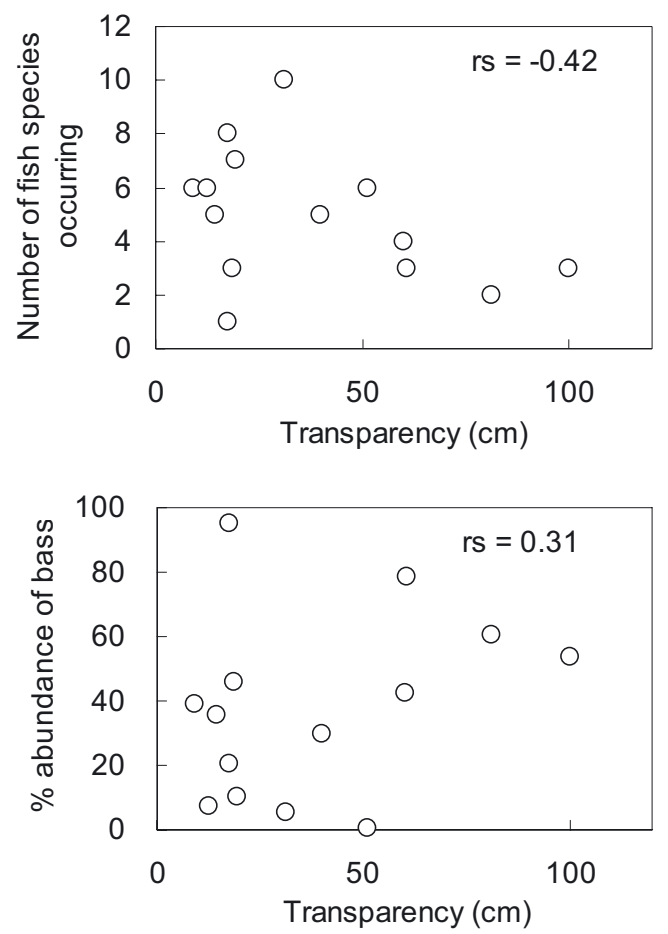

Fig. 4. Correlation between species richness of pond-dwelling fish assemblages, relative abundance of exotic largemouth bass and transparency.

vegetation cover generally benefits many fishes by providing habitat heterogeneity (Eadie and Keast 1984), breeding and feeding sites (Werner et al. 1978, 1983), and refuge to avoid predation (Gotceitas and Colgan 1989; Persson and Eklöv 1995; Warfe and Barmuta 2004). However, for the interaction of prey and largemouth bass, only dense aquatic vegetation cover functions as a refuge (Savino and Stein 1982, 1989; Gotceitas and Colgan 1989). In the study ponds, because floating-leaved plant species (Trapa japonica and Nymphaea tetragona) were found and were more predominant in the pond surface than emergent vegetation (see Table 1), the floating vegetation cover might have less structural complexity to provide refuge for prey. In addition, some previous studies reported that piscivorous fish habituated under floating vegetation covers more frequently than submersed beds or opened habitats (e.g. Meerhoff et al. 2003; Teixeira-de Mello et al. 2009). Because largemouth bass switch to a more efficient ambushing strategy in structured habitats (e.g. sparse vegetation coverage) (Anderson 1984; Savino and Stein 1989), floating vegetation cover might be beneficial for exotic bass as foraging sites. Although Maezono and Miyashita (2003) identified that bluegill (Lepomis macrochirus) tend to reduce the impact of bass, and that some small-bodied cyprinids (e.g., P. parva or $R$. ocellatus ocellatus) and bass do co-occur in Japanese small pond systems, bluegill or related centrarchids had never lived in the study ponds. Thus, effects of both exotic largemouth bass and some environmental factors influencing their predatory efficiency influenced the structuring of fish assemblages in the studied ponds.

In addition to predation by piscivorous species, a number of abiotic factors influence the structure of fish assemblages (reviewed in Jackson et al. 2001). In small pond systems, connectivity to other water bodies (for maintaining fish migration) is a critical factor for the structuring of fish assemblages, because the local extinction rate seems to be relatively high as a result of stressful conditions (e.g. drying up or anoxia) and small population sizes in those systems (Uchida and Inoue 2010; Mitsuo et al. 2011). In fact, connectivity (i.e. presence/absence of inflow channel and size of inflow channel) was the critical factor for maintaining species richness of pond-dwelling fish assemblages without bass in our study area (Mitsuo et al. 2011). In the present study, however, there was no relationship between species richness and environmental $P C 1$ scores, which included size of the inflow channel as a positive factor. Given that different factors influenced fish species richness between ponds with and without bass, our findings suggest that the invasion of exotic bass is the main critical factor altering the structuring of fish assemblages in small pond systems.

\subsection{Gradients in the effects of exotic largemouth bass on the relative abundance of fishes}

The present study showed that the effects of exotic largemouth bass and environmental factors on relative abundance distinctly differed among species. Relative abundances of three cyprinid species, $R$. ocellatus ocellatus, $P$. parva and Carassius sp., were significantly affected by the predominance of bass. Moreover, relative abundances of $P$. parva and Carassius sp. significantly correlated with environmental $P C 2$ and/or $P C 3$ scores, indicating that they were negatively related to transparency and vegetation coverage. All of the three species are common small-bodied lentic-nekton cyprinids (Miyadi et al. 1976), and seemed to be vulnerable to predation by bass. Some previous studies reported that those species dramatically decreased or were eliminated from lakes and ponds invaded by bass (Maezono and Miyashita 2003; Sugimura and Jinguji 2005; Tsunoda et al. 2010). On the other hand, the relative abundances of the remaining four species did not significantly correlate with that of exotic bass. While the reasons for these results could not be clarified, the ecological traits and/or body size of those species might influence their vulnerability to bass predation. For example, adult Cyprinus carpio are too large for bass to predate. It was also reported that two demersal species, $M$. anguillicaudatus and Rhinogobius sp., often co-occurred or coexisted with exotic bass in Japanese lakes and ponds (Sugiyama and Jinguji 2005; Tsunoda et al. 2009, 2010). Only the relative abundance of $Z$. platypus positively correlated with environmental $P C 1$ scores. In the present study, mean depth, $D O$ and size of inflow channel were all positive factors on environmental $P C 1$ (see Table 1). Z. platypus is very sensitive and intolerant to hypoxia (Yamamoto and Hirano 1988). In addition, although our study period excluded winter, the species mainly distributed deeper water of lentic system during winter (Miyadi et al. 1976). Thus, it is likely that relative abundance of Z. platypus was mainly associated with environmental conditions and not affected by predominance of exotic bass. 


\section{Conclusion}

The present study shows that exotic largemouth bass have a critical influence on fish assemblages in small pond systems. However, this is mediated by some environmental factors that affect the predatory efficiency of bass (for example, lower transparency). Our findings indicate that the impact of invasive piscivores could be buffered by improvements in or alteration of these environmental characteristics; e.g. water turbidity is increased by removal of aquatic macrophytes or introduction/propagation of plaktivorous and benthivorous fishes (Meijer et al. 1990; Perrow et al. 1997; Lougheed et al. 1998; Scheffer et al. 1998). However, we believe that the cooccurrence of exotic bass and native fishes within small pond systems is likely to be transient and changeable according to changes in the pond environments. Thus, countermeasures such as removal or population control of exotic bass would be needed for conserving and maintaining native fish populations. We showed that the effects of exotic bass were most serious for small-bodied lentic cyprinids in small pond systems. Because farm ponds in the agricultural irrigation system are important habitats for lentic cyprinid species, including threatened ones (e.g. some species of Acheilognathus; Mitsuo et al. 2010), the removal of the predatory impacts of exotic bass is necessary for the conservation of fish species biodiversity in agricultural landscapes.

Acknowledgements. We are grateful to the students of the Faculty of Agriculture, Tokyo University of Agriculture and Technology for helping with the field surveys. We also thank Professor Y. Senga (Tokyo University of Agriculture and Technology) and Oshu City administrators for their cooperation. We are grateful to the editor and two anonymous reviewers for their fruitful comments. This study was supported by a Grant-in-Aid for Scientific Research (No.1965808) and the Japan Society for the Promotion of Science (JSPS) Research Fellowships for Young Scientists (20-3522).

\section{References}

Abekura K., Hori M., Takemon Y., 2004, Changes in fish community after invasion and during control of alien fish population in Mizoro-ga-ike, Kyoto city. Glob. Environ. Res. 8, 145-154.

Anderson O., 1984, Optimal foraging by largemouth bass in structured environments. Ecology 65, 851-861.

Azuma M., Motomura Y., 1998, Feeding habits of largemouth bass in a non-native environment: the case of a small lake with bluegill in Japan. Environ. Biol. Fish. 52, 379-389.

Bertolo A., Magnan P., 2006, Spatial and environmental correlates of fish community structure in Canadian Shield lakes. Can. J. Fish. Aquat. Sci. 63, 2780-2792.

Brönmark C., Hansson L.-A., 2005, The Biology of Lakes and Ponds. second edition, New York, Oxford University Press.

Chapleau F., Findlay C.S., Szenasy E., 1997, Impact of piscivorous fish introductions on fish species richness of small lakes in Gatineau Park, Quebec. Ecoscience 4, 259-268.

Eadie J.M., Keast A., 1988, Resource heterogeneity and fish species diversity in lakes. Can. J. Zool. 62, 1689-1695.

Godinho F.N., Ferreira M.T., 1998, The relative influences of exotic species and environmental factors on an Iberian native fish community. Environ. Biol. Fish. 51, 41-51.
Gotceitas V., Colgan P., 1989, Predator foraging success and habitat complexity: quantitative test of the threshold hypothesis. Oecologia 80, 158-166.

Howick G.L., O'Brien W.J., 1983, Piscivorous feeding behavior of largemouth bass: an experimental analysis. Trans. Am. Fish. Soc. 112, 508-516.

Jackson D.A., Peres-Neto P.R., Olden J.D., 2001, What controls who is where in freshwater fish communities - the roles of biotic, abiotic, and spatial factors. Can. J. Fish. Aquat. Sci. 58, 157-170.

Jackson D.A., 2002, Ecological effects of Micropterus introductions: the dark side of black bass. In: Philipp D.P., Ridgway M.S. (eds.) Black bass: ecology, conservation, and management, Bethesda, ML American Fisheries Society, pp. 221-232.

Kadono Y., 1998, Aquatic plants community in farm pond (in Japanese). In: Ezaki Y., Tanaka T. (eds.). Preservation of waterside environment, Tokyo, Asakura Shoten, pp. 1-16.

Kaneko S., Wakabayashi T., 1998, The history of introduction of black bass (in Japanese), Tokyo, Tsuribitosha.

Kaufman L., 1992, Catastrophic change in species-rich freshwater ecosystems. Bioscience 42, 846-858.

Keast J.A., Webb D., 1966, Mouth and body form relative to feeding ecology in the fish fauna of a small lake Opinicon, Ontario. J. Fish. Res. Board Can. 23, 1862-1873.

Kuge T., Nobusawa K., Maita M., 2004, Abundance and feeding habits of largemouth bass Micropterus salmoides in Haruna Lake, Gunma prefecture, Japan (in Japanese with English summary). Suisanzoshoku 52, 73-80.

Lougheed V.L., Crosbie B., Chow-Fraser P., 1998, Predictions on the effect of common carp (Cyprinus carpio) exclusion on water quality, zooplankton, and submergent macrophytes in a Great Lakes wetland. Can. J. Fish. Aquat. Sci. 55, 1189-1197.

MacRae P.S.D., Jackson D.A., 2001, The influence of smallmouth bass (Micropterus dolomieu) predation and habitat complexity on the structure of littoral zone fish assemblages. Can. J. Fish. Aquat. Sci. 58, 342-351.

Maezono Y., Miyashita T., 2003, Community-level impacts induced by introduced largemouth bass and bluegill in farm ponds in Japan. Biol. Conserv. 109, 111-121.

Maezono Y., Kobayashi R., Kusahara M., Miyashita T., 2005, Direct and indirect effects of exotic bass and bluegill on exotic and native organisms in farm ponds. Ecol. Appl. 15, 638-650.

Meerhoff M., Mazzeo N., Moss B., Rodriguez-Gallego L., 2003, The structuring role of free-floating versus submerged plants in a subtropical shallow lake. Aquat. Ecol. 37, 377-391.

Meijer M.-L., de Haan M.W., Breukelaar A.W., Buiteveld H., 1990, Is reduction of the benthivorous fish an important cause of high transparency following biomanipulation in shallow lakes? Hydrobiologia, 200/201, 303-315.

Mitsuo Y., Ohira M., Tsunoda H., Shono Y., Senga Y., 2010, The fish fauna of farm ponds in northeastern Japan and its contribution to the maintenance of regional fish diversity. J. Environ. Inform. Sci. 38, 89-96.

Mitsuo Y., Tsunoda H., Takiguchi A., Senga Y., 2011, Environmental influences on fish assemblages in irrigation ponds. Aquat. Ecol. 45, 473-482.

Miyadi D., Kawanabe H., Mizuno N., 1976, Colored illustrations of the freshwater fishes of Japan (New edition completely revised) (in Japanese with English summary), Osaka, Hoikusha.

Moyle P.B., Light T., 1996, Biological invasions of fresh water: empirical rules and assembly theory. Biol. Conserv. 78, 149-161.

Nowlin W.H., Drenner R.W., Guckenberger K.R., Lauden M.A., Alonso G.T., Fennell J.E., Smith J.L., 2006, Gape limitation, prey size refuges and the top-down impacts of piscivorous largemouth bass in shallow pond ecosystems. Hydrobiologia 563, 357-369. 
Oksanen J., Kindt R., Legendre P., O'Hara B., Gavin L., Simpson G.L., Stevens M.H.H., 2008, Vegan: community ecology package. R package version 1.11-4. http://cran.r-project.org/, http://vegan.r-forge.r-proect.org/

Perrow M.R., Meijer M.-L., Dawidowicz P., Coops H., 1997, Biomanipulation in shallow lakes: state of the art. Hydrobiologia, 342/343, 355-365.

Persson L., Eklöv P., 1995, Prey refuges affecting interactions between piscivorous perch and juvenile perch and roach. Ecology 76, 70-81.

Polis G.A., Strong D.R., 1996, Food web complexity and community dynamics. Am. Nat. 147, 813-846.

Rahel F.J., 1984, Factors structuring fish assemblages along a bog lake successional gradient. Ecology 65, 1276-1289.

Rahel F.J., 2002, Homogenization of freshwater faunas. Ann. Rev. Ecol. Syst. 33, 291-315.

R Development Core Team, 2009, R: a language and environment for statistical computing, Vienna, R Foundation for Statistical Computing.

Sass G.G., Gille C.M., Hinke J.T., Kitchell J.F., 2006, Whole-lake influences of littoral structural complexity and prey body morphology on fish predator-prey interactions. Ecol. Freshw. Fish. 15, 301-308.

Savino J.F., Stein R.A., 1982, Predator-prey interaction between largemouth bass and bluegills as influenced by simulated, submersed vegetation. Trans. Am. Fish. Soc. 111, 255-266.

Savino J.F., Stein R.A., 1989, Behavioural interactions between fish predators and their prey: effects of plant density. Anim. Behav. 37, 311-321.

Scheffer M., 1998, Ecology of Shallow Lakes, London, Chapman and Hall.

Shoup D.E., Wahl D.H., 2009, The effects of turbidity on prey selection by piscivorous largemouth bass. Trans. Am. Fish. Soc. 138, $1018-1027$.

Strong D.R., 1992, Are trophic cascades all wet? Differentiation and donor-control in species ecosystems. Ecology 73, 747-754.

Sugiyama T., Jinguji H., 2005, Impact and extermination of largemouth bass in irrigation pond (in Japanese). J. Jap. Soc. Irrig. Drain. Rural. Eng. 73, 797-800.

Teixeira-de Mello F., Meerhoff M., Pekcan-Hekim Z., Jeppesen E., 2009, Substantial differences in littoral fish community structure and dynamics in subtropical and temperate shallow lakes. Freshw. Biol. 54, 1202-1215.

Tonn W.M., Magnuson J.J., 1982, Patterns in the species composition and richness of fish assemblages in northern Wisconsin lakes. Ecology 63, 1149-1166.
Tonn W.M., Magnuson J.J., Rask M., Toivonen J., 1990, Intercontinental comparison of small-lake fish assemblages: the balance between local and regional processes. Am. Nat. 136, 345-375.

Tsunoda H., Senga Y., Watanabe M., 2009, Feeding habits of largemouth bass in Lakes Saiko and Shojiko (in Japanese with English summary). Wildl. Conserv. Jap. 12, 1-11.

Tsunoda H., Mitsuo Y., Ohira M., Doi M., Senga Y., 2010, Change of fish fauna in ponds after eradication of invasive piscivorous largemouth bass, Micropterus salmoides, in north-eastern Japan. Aquat. Conserv. Mar. Freshw. Ecosyst. 20, 710-716.

Uchida Y., Inoue M., 2010, Fish species richness in spring-fed ponds: effects of habitat size versus isolation in temporally variable environments. Freshw. Biol. 55, 983-994.

Warfe D.M., Barmuta L.A., 2004, Habitat structural complexity mediates the foraging success of multiple predator species. Oecologia 141, 171-178.

Webb P.W., 1986, Effects of body form and response threshold on the vulnerability of four species of teleost prey attacked by largemouth bass (Micropterus salmoides). Can. J. Fish. Aquat. Sci. 43, 763-771.

Welcomme R.L., 1992, A history of international introductions of inland aquatic species. ICES J. Mar. Sci. 194, 3-14.

Werner E.E., Hall D.J., Werner M.D., 1978, Littoral zone fish communities of two Florida lakes and a comparison with Michigan lakes. Environ. Biol. Fish. 3, 163-172.

Werner E.W., Gilliam J.F., Hall D.J., Mittelbach G.G., 1983, An experimental test of the effects of predation risk on habitat use in fish. Ecology 64, 1540-1548.

Whittier T.R., Kincaid T.M., 1999, Introduced fish in northeastern USA lakes: regional extent, dominance and effects on native species richness. Trans. Am. Fish. Soc. 128, 769-783.

Yamamoto K., Hirano O., 1988, Changes of oxygen consumption in rose bitterling, field gudgeon, common minnow, dark chub and common carp under progressive hypoxia (in Japanese with English summary). Suisanzoshoku 36, 45-48.

Yodo T., Kimura S., 1998, Feeding habits of largemouth bass Micropterus salmoides in lakes Shorenji and Nishinoko, central Japan (in Japanese with English summary). Nippon Suisan Gakkaishi 64, 26-38.

Yodo T., Iguchi K., 2004, A review on the black bass problem referring to the historical background in Japan (in Japanese with English summary). Bull. Fish. Res. Agency 12, 10-24.

Yonekura R., Kita M., Yuma M., 2004, Species diversity in native fish community in Japan: comparison between non-invaded and invaded ponds by exotic fish. Ichthyol. Res. 51, 176-179. 